
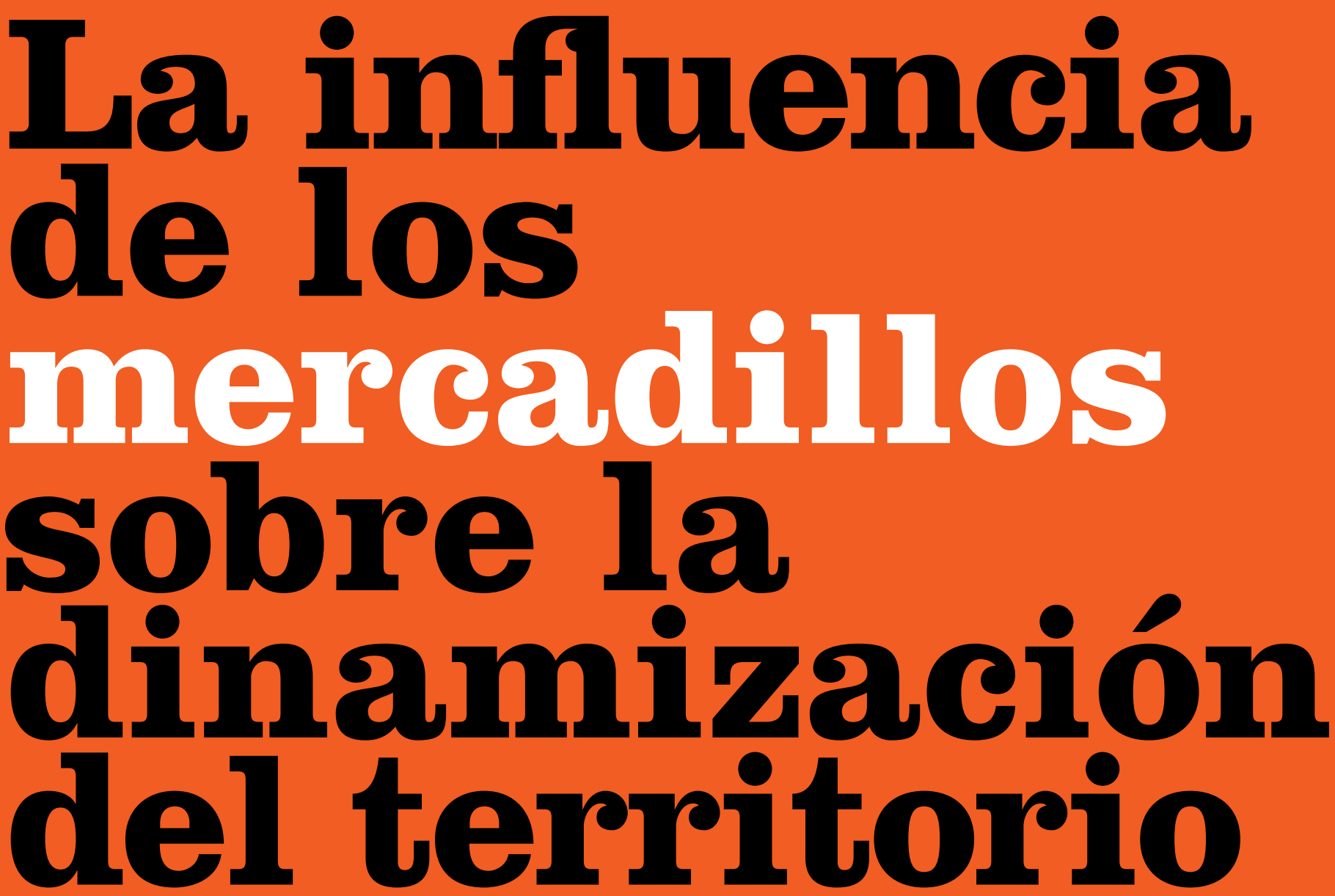

Belén Pardos

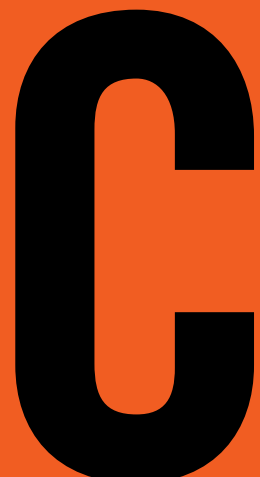

omparar precios, encontrar piezas únicas o dar un paseo entre los puestos. Los fines de semana suelen ser el momento escogido por la ciudadanía para acercarse a los tradicionales mercadillos locales a pasar la mañana. Pero los mercados de venta no sedentaria conviven con el resto de comercios en muchas poblaciones y ciudades del mundo, durante varios días a lo largo del año. Su influencia sobre el territorio y sobre el resto del comercio ha suscitado el interés del doctorando y profesor de la Universidad Miguel Hernández (UMH) de Elche Ignacio Serrano Guillén, quien ha analizado cómo los mercadillos contribuyen a dinamizar los territorios.
Ignacio Serrano cuenta que se sorprendió al detectar que en la actualidad existe una gran demanda de creación de mercados de venta no sedentaria. Con gran tradición en muchas localidades nacionales, en otros países europeos cuentan con infraestructuras provistas de instalaciones y servicios y son un atractivo para el turismo. En la Comunidad Valenciana, la legislación otorga una concesión de 15 años a quienes comercian en este tipo de emplazamientos. El doctor por la UMH explica que la directiva que regula los mercados de venta no sedentaria lleva ya en vigor 8 o 9 años, por lo que en un periodo breve de tiempo se producirá un cambio.

La ley contempla que los puestos deben salir a concurso público, porque el número de plazas es limitado. A juicio del autor de la tesis, se debería adaptar la normativa de acuerdo con la demanda actual: "Si en un momento de paro y crisis se piden más puestos, hay una demanda no satisfecha, se trata de un campo en crecimiento". Serrano Guillén observó que el fenómeno de aumento de peticiones para la creación de mercadillos era mayor en municipios turísticos. Por este motivo, el doctor intentó analizar los factores que influyen en el tamaño y la creación de estos mercados de venta no sedentaria.

\section{La investigación}

Para llevar a cabo el estudio, el doctorando desarrolló un análisis de fuentes secundarias. Es decir, una correlación de municipios con el número de puestos existentes, así como la cantidad de puestos en función del tamaño de la población o de la capacidad de compra. Una de las mayores dificultades que Ignacio Serrano Guillén ha encontrado para realizar el estudio es la falta de trabajos previos en este ámbito. "Encontré un trabajo de la 


\section{- Stath}

$(0, x-y)$
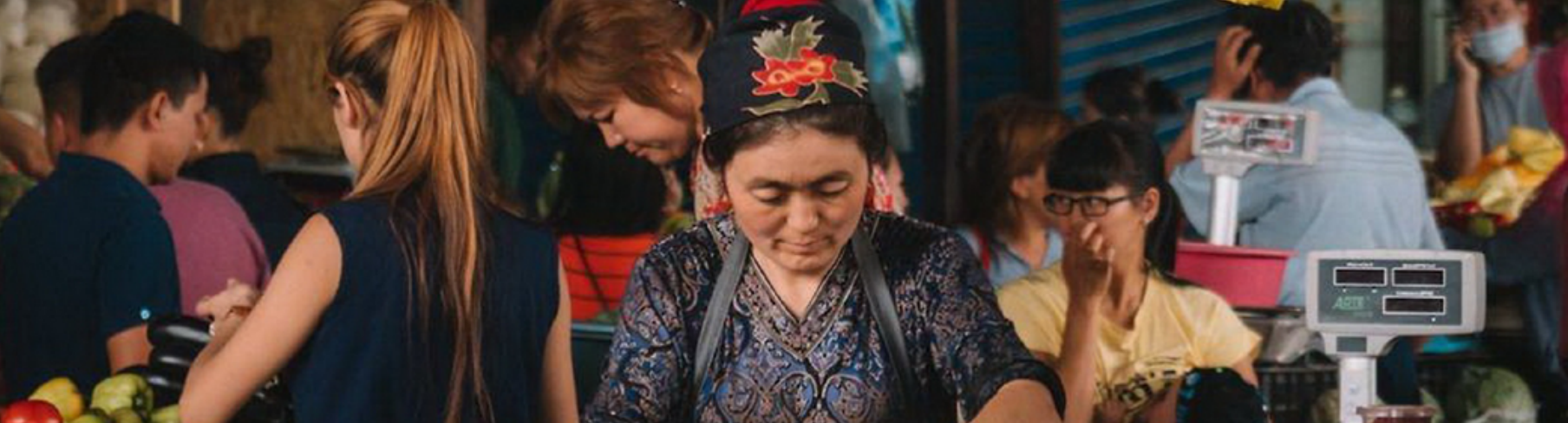

$2 x$

acese

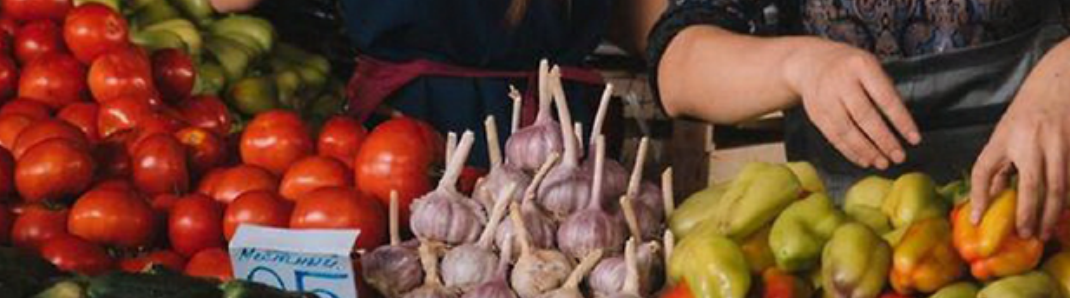

- minar $4: 84$
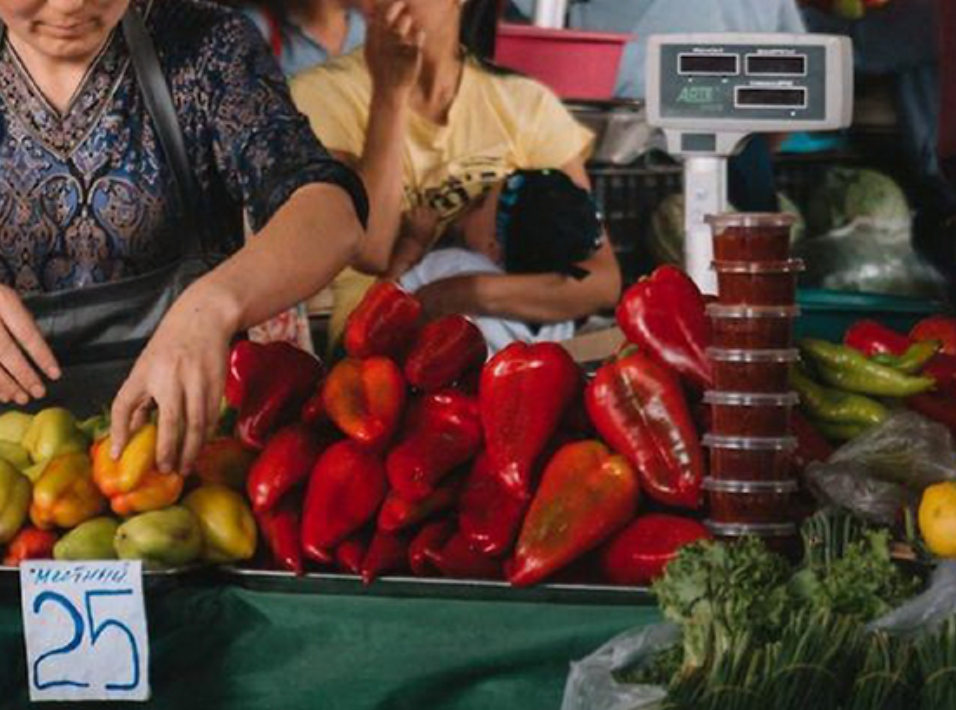
Fundación 'la Caixa' en el que se medía la cuota de mercado, que es la capacidad de compra de los ciudadanos de un territorio según una serie de índices", cuenta. A partir de este trabajo, el investigador introdujo numerosas variables en el modelo para quedarse finalmente con las tres más significativas: la capacidad de compra de los ciudadanos del territorio, el índice turístico y el índice comercial. Estos últimos miden el porcentaje de empresas de actividad económica relacionadas con el turismo y con el comercio presentes en un territorio, respecto de la nación, que tienen relación con el tamaño de los mercados.

Una vez construido el modelo, Serrano Guillén repara que en la provincia de Alicante, ámbito de aplicación de su estudio, existen localidades con más puestos de venta no sedentaria de los que habría según el modelo y otros con menos. A partir de esta revelación, el investigador elimina los municipios extremos y se queda con dos de referencia: El Campello y Santa Pola.

Según el modelo, Campello es un municipio con menos puestos de los que le corresponderían y, por su parte, Santa Pola cuenta con más de los que debería. El investigador explica que le sorprendió la diferencia, a pesar de que se trata de dos localidades con una idiosincrasia muy parecida: ambas son costeras y se encuentran cerca dos grandes cabeceras comerciales, Alicante y Elche, a una distancia similar y, en ambos casos, el turismo les influye. Con el objetivo de profundizar más en la investigación, el doctor por la UMH pasó a utilizar fuentes primarias. En concreto, encuestas y entrevistas en profundidad a vendedores de los propios mercadillos, a los comercios del municipio y a la ciudadanía. Además, cuenta, empleó como técnica adicional las entrevistas en profundidad a políticos, empresarios y amas de casa, así como el método de la observación.

\section{Los resultados}

Una vez desarrollado el trabajo de campo, Ignacio Serrano concluye que, a pesar de su hipótesis inicial, los comerciantes sí están a favor de tener próximo un mercado de venta no sedentaria porque les beneficia. "Aunque en un momento dado podía parecer una competencia, la presencia de los mercadillos conlleva que se visiten también estas tiendas", asegura.
Entre la ciudadanía, los mayores y los turistas son quienes más lo demandan. Por su parte, las personas con edad laborable tienen preferencia sobre el fin de semana, que es cuando pueden acudir. Los vendedores, como ya suelen tener 4 o 5 días ocupados vendiendo en diferentes mercados, son quienes menos quieren que crezca.

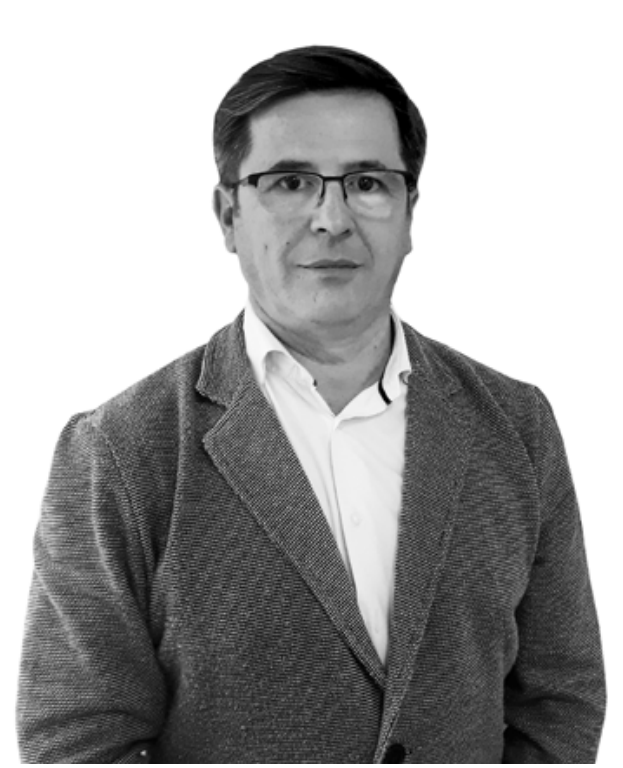

\section{Ignacio Serrano $-$ \\ Autor de la Tesis Doctoral}

"Al realizar las entrevistas en profundidad, reparó en que el hecho de que los mercadillos hayan crecido en Santa Pola más que en El Campello viene motivado porque, históricamente, el porcentaje de puestos ocupados por residentes del municipio es mucho mayor en Santa Pola que en El Campello", explica Serrano Guillén. Por este motivo, aclara el autor de la tesis, la demanda de puestos por parte de los propios residentes en Santa Pola ha derivado en un mayor crecimiento. En aquellos enclaves donde no ha habido una demanda interna de puestos, sino que ha sido externa, no ha existido la misma presión y el crecimiento ha sido menor, como en el caso de El Campello. De esta manera, el análisis permite concluir los factores que han influido en el crecimiento, como la propia demanda local.

\section{Los comer- ciantes sí están a favor de tener próximo un mercado de venta no sedentaria porque les
beneficia}

El enfoque de la tesis de Ignacio Serrano está relacionado, sobre todo, con la empleabilidad. El investigador de la UMH subraya que los mercados de venta no sedentaria se han convertido en refugio para quienes han perdido su puesto de trabajo. "Además, cuando existe un gran arraigo familiar, como es el caso de las personas de etnia gitana, existe un gran interés en incrementar el número de trabajadores", apunta. El resultado del trabajo abre el interrogante sobre qué va a suceder cuando se acaben las concesiones dentro de 7 años: "Cuando este colectivo, en el que el $60 \%$ trabaja en este tipo de formato comercial, compita contra otro tipo de entidades". Como no se prima que hayan trabajado con anterioridad en mercados de venta no sedentaria, competirán de igual a igual. Por este motivo, el investigador de la UMH señala que puede aparecer un conflicto ya que este formato comercial ha dado un sustento de vida a colectivos que estaban excluidos. Ignacio Serrano apunta que sería positivo estudiar medidas que primen haber trabajado en mercadillos durante cierto periodo de tiempo, con el fin de aprovechar los beneficios en materia de empleabilidad de los mercados de venta no sedentaria. Además, Ignacio Serrano apuesta por que en el futuro se llegue a mejorar las infraestructuras: "De manera que sean más accesibles y cómodas para la ciudadanía, dada la creciente demanda". 